\title{
PROGRAM KEMITRAAN MASYARAKAT (PKM) PENGRAJIN DAUR ULANG SAMPAH
}

\author{
Devi Endah Saraswati $\left.{ }^{*} 1\right)$; Frenty Rohmawati \\ 1) Prodi Kebidanan; Stikes Insan Cendekia Husada Bojonegoro \\ Jl. dr. Wahidin No. 68A; Bojonegoro; Jawa Timur; Indonesia
}

\begin{abstract}
Abstrak
Sampah plastik akan berdampak negatif terhadap lingkungan karena tidak dapat terurai dengan cepat dan dapat menurunkan kesuburan tanah. Sampah plastik yang dibuang sembarangan juga dapat menyumbat saluran drainase, selokan dan sungai sehingga bisa menyebabkan banjir. Sampah plastik yang dibakar bisa mengeluarkan zat-zat yang berbahaya bagi kesehatan manusia. Semakin meningkatnya sampah plastik ini akan menjadi masalah serius bila tidak dicari penyelesaiannya. Dengan ini diperlukan alat khusus untuk pengolahan sampah plastik menjadi minyak, material yang dapat membantu proses pengolahan sampah plastik menjadi minyak dan penerapannya sebagai bahan bakar mesin. Metode yang diguanakan yaitu pengkajian/survei dilanjutkan dengan pelaksanaan sosialisasi pengurangan penggunaan sampah plastik dan dilanjutkan dengan pengadaan alat daur ulang untuk sampah plastik serta sosialisasi penggunaan alat tersebut. Alat pengolahan sampah plastik menjadi bahan bakar minyak dapat digunakan dan dimanfaatkan sebagai salah satu upaya untuk mengurangi sampah plastik sehingga memiliki nilai jual bagi warga desa Mojodeso, kecamatan Kapas Kabupaten Bojonegoro.
\end{abstract}

Kata kunci: Pengrajin; Daur Ulang; Sampah

\begin{abstract}
[COMMUNITY PARTNERSHIP PROGRAM (PKM) CRAFT RECYCLING] Plastic waste will have a negative impact on the environment because it cannot decompose quickly and can reduce soil fertility. Plastic waste that is dumped carelessly can also clog drainage channels, ditches and rivers so that it can cause flooding. Burned plastic waste can remove substances that are harmful to human health. Increasing plastic waste will become a serious problem if the solution is not sought. With this, special tools are needed to process plastic waste into oil, a material that can help the processing of plastic waste into oil and its application as enginefue The method used was an assessment / survey followed by the dissemination of the reduction of the use of plastic waste and was determined by the procurement of recycling equipment for plastic waste and the socialization of the use of these tools. Plastic waste processing into fuel oil equipment can be used and utilized as an effort to reduce plastic waste so that it has a selling value for the people of Mojodeso village, Kapas district, Bojonegoro Regency
\end{abstract}

Keywords: Craftsman; recycle; garbage

\section{Pendahuluan}

Penggunaan plastik dalam kehidupan manusia semakin lama semakin meningkat. Peningkatan pemanfaatan plastik ini terjadi karena plastik bersifat ringan, praktis, ekonomis dan dapat menggantikan fungsi dari

*) Correspondence author (Devi Endah Saraswati)

E-mail: deviendah.stikesicsada@gmail.com barang-barang lain. Sifat praktis dan ekonomis ini menyebabkan plastik sering dijadikan barang sekali pakai, sehingga semakin banyaknya penggunaan perlengkapan dari bahan plastik tersebut, menyebabkan semakin banyak pula sampah-sampah plastik. Sampah plastik akan berdampak negatif terhadap lingkungan karena tidak dapat terurai dengan cepat dan dapat 
menurunkan kesuburan tanah. Sampah plastik yang dibuang sembarangan juga dapat menyumbat saluran drainase, selokan dan sungai sehingga bisa menyebabkan banjir ${ }^{1}$.

Sampah plastik yang dibakar bisa mengeluarkan zat-zat yang berbahaya bagi kesehatan manusia. Semakin meningkatnya sampah plastik ini akan menjadi masalah serius bila tidak dicari penyelesaiannya. Penanganan sampah plastik yang populer selama ini adalah dengan 3R (Reuse, Reduce, Recycle). Reuse adalah memakai berulang kali barang-barang yang terbuat dari plastik. Reduce adalah mengurangi pembelian atau penggunaan barang-barang dari plastik, terutama barang-barang yang sekali pakai. Recycle adalah mendaur ulang barang-barang yang terbuat dari plastik. Masing-masing penanganan sampah tersebut di atas mempunyai kelemahan. Kelemahan dari reuse adalah barang-barang tertentu yang terbuat dari plastik, seperti kantong plastik, kalau dipakai berkali-kali akan tidak layak pakai. Selain itu beberapa

jenis plastik tidak baik bagi kesehatan tubuh apabila dipakai berkali-kali. Kelemahan dari reduce adalah harus tersedianya barang pengganti plastik yang lebih murah dan lebih praktis. Sedangkan kelemahan dari recycle adalah bahwa plastik yang sudah didaur ulang akan semakin menurun kualitasnya. Alternatif lain penanganan sampah plastik yang saat ini banyak diteliti dan dikembangkan adalah mengkonversi sampah plastik menjadi bahan bakar minyak ${ }^{2}$.

Permasalah sampah tersebut tidak hanya terdapat di daerah perkotaan atau daerah industri tetapi terjadi di seluruh daerah pedesaan. Untuk mengurai masalah sampah maka perlu dilakukan pendekatan kepada masyarakat dalam bentuk pengabdian masyarakat. Pengabdian masyarakat ini merupakan Program Kemitraan Masyarakat dengan pengrajin daur ulang sampah di Desa Mojodeso Kecamatan Kapas Kabupaten Bojonegoro. Mitra dari program ini adalah Bank Sampah Payung Sejahtera dan UD Jaya Makmur

Permasalahan yang dihadapi oleh Mitra (Desa Mojodeso) adalah banyaknya sampah kantong plastik (kresek) yang tidak dapat dimanfaatkan ulang menjadi kerajinan dan apabila dijual jurstu mengalami kerugian karena harga yang sangat rendah, selain itu masalah yang dihadapi adalah terbatasnya pemasaran dari hasil kerajinan sampah plastik yaitu hanya dipasarkan di sekitar desa dan jika terdapat event - event kegiatan.
Tujuan dari Program Kemitraan Masyarakat ini adalah untuk memberikan solusi permasalahan mitra dan dapat meningkatkan kualitas mitra.

\section{Metode}

Metode dari Program Kemitraan Masyarakat ini adalah :

1. Analisa Situasi Masyarakat

Analisa situasi masalah merupakan awal yang sangat penting untuk menentukan khalayak sasaran dan bidang permasalahan yang akan dianalisis

2. Identifikasi Masalah

Hasil analisis yang mencakup sasara dan bidang permasalahan kemudian dirumuskan masalah yang dihadapi oleh masyarakat dari sasaran yang terpilih.

3. Menentuan Tujuan Kegiatan

Pada tahap ini dapat ditentukan kondisi baru yag dihasilkan dari kegiatan pengabdian yang dilakukan, sehingga dapat dibedakan kondisi sekarang dan kondisi baru yang ingin dicapai pada kegiatan pengabdian masyarakat.

4. Rencana Pemecahan Masalah

Masalah yang sudah dirumuskan perlu di pecahkan sekaligus untuk mencapai tujuan yang telah ditetapkan. Dalam rencana pemecahan masalah terdapat du atahapp yaitu : mencari alternatif pemecahan masalah dan memilih salah satu alternatif yang terbaik.

5. Pendekatan Sosial

Prinsip dari pendekatan sosial adalah masyarakat sasaran dijadikan subyek bukan sebagai obyek dari kegiatan Untuk itu masyarakat harus ditumbuhkan kesadaran bahwa masalah yang dirumuskan adalah masalah mereka dan perlu dipecahkan oleh mereka. Selanjutnya jika mereka tidak dapat menyelesaikan bisa meminta bantuan kepada perguruan tinggi.

6. Pelaksanaan Kegiatan

Pada tahap ini perlu di rencanakan secara matang dan terinci yang meliputi :

a. Bagaimana kegiatan ini akan dilakukan

b. Waktu pelaksanaan

c. Tempat kegiatan

d. Orang yang terliba

Dalam pelaksanaan kegiatan ini pertumbuhan dan rasa tanggung jawab masyarakat sangat penting untuk keberhasilan kegiatan, sebaiknya dihindarkan anggpan bahwa kegiatan ini merupakan 
kegiatan untuk kepentingan perguruan tinggi sehingga masyarakat hanya bersifat membantu.

7. Evaluasi Kegiatan dan Hasil

Setiap tahapan perlu dievaluasi untuk mengetahui keberhasilan yang telah dicapai. Dalam evaluasi tetap melibatkan masyarakat agar masyarakat mengetahui hasil dari kegiatan selama ini dan belajar bagaimana mengukur hasil serta dapat melakukan penyempurnaan - penyempurnaan dari kegiatan dan kurang maksimal.

Serangkaian Kegiatan Program Kemitraan Masyarakat ini dilakukan pada bulan Februari sampai November 2018 di Desa Mojodeso, Kecamatan Kapas, Kabupaten Bojonegoro, Provinsi Jawa Timur. Program Kemitraan Masyarakat ini dilakukan dengan 2 mitra di Desa Mojodeso yaitu Bank Sampah Payung Sejahtera dan UD Jaya Makmur... Program Kemitraan Masyarakat ini menekankan pada pemberdayaan dan pengembangan masyarakat untuk lebih potensial di bidang pengetahuan, keterapilan dan secara ekonomi.

\section{Hasil dan Pembahasan}

1. Hasil Situasi Masyarakat

$\begin{array}{cccc}\begin{array}{c}\text { Sasaran } \\ \text { Masyarakat }\end{array} \text { adalah } & \begin{array}{c}\text { Program } \\ \text { Desa }\end{array} & \begin{array}{r}\text { Kegiatan } \\ \text { Mojodeso }\end{array}\end{array}$
Kecamatan Kapas, Kabupaten Bojonegoro. Desa Mojodeso ini terdiri dari 15 RT dan terdapat 2 bidang usaha di bidang pengolahan sampah yang digunakan sebagi mitra dalam pengabdian masyarakat.

Mitra yang pertama adalah Bank Sampah Payung Sejahtera dan UD Jaya Makmur. Bank sampah Payung sejahtera merupakan unit usaha di desa yang bergerak di bidang pengolahan sampah plastik atau sampah anorganik, sedangkan UD Jaya Makmur berherak di bidang pengolahan sampah organik

2. Indentifikasi Masalah

Permasalahan yang di hadapi mitra Bank Sampah Payung Sejahtera adalah tentang banyaknya sampah kantong plastik yang sulit diurai oleh lingkungan dan tidak dapat di daur ulang sebagai kerajinan dan terbatasnya pemasaran hasil kerajinan daur ulang sampah yang hanya dipasarkan di lingkungan sekitar dan setiap ada event kegiatan. Sedangkan permasalahan yang dihadapi oleh UD jaya Makmur adalah adanya biogas yang belum dimanfaatkan secara maksimal.
Sampah plastik yang diproduksi secara terus menerus dan tidak dapat diolah menjadi masalah yang perlu segera diatasi.

3. Tujuan Kegiatan

Setelah menganalisis dari permasalahan yang ada tujuan dari kegiatan ini adalah terciptaya kondisi lingkungan yang bebas dari permasalahan sampah kantong plastik dengan pemberdayaan potensi yang diimiliki oleh masyarakat

4. Rencana Pemecahan Masalah Rencana pemecahan masalah dengan melibatkan masyarakat antar lain :

a. Sosialisasi pengurangan penggunaan sampah kantong plastik

b. Pegurusan Surat Ijin Usaha Perdagangan (SIUP) serta merk dagang

c. Pengadaan alat daur ulang sampah plastik menjadi bahan bakar minyak (BBM)

d. Sosialisasi penggunaan alat daur ulang sampah menjad bahan bakar minyak (BBM)

5. Pendekatan Sosial

Keberhasilan suatau kegiatan tidak luput dari peran serta masyarakat yang sebagai pemeran utama dari kegiatan. Pendekatan sosila yang dilakukan tidak hanya kepada kepala desa dan perangkat desa tetapi kepada semua masyarakat Desa Mojodeso.

6. Pelaksanaan Kegiatan

a. Kegiatan sosialisasi pengurangan sampah plastik

Kegiatan ini berbentuk seminar yang dilakukan di desa Mojodeso dan dihadiri oleh Kepala Desa, Ketua STIKes Insan Cendekia Husada Bojonegoro serta pengurus Bank Sampah dari RT 1 sampai RT 15. Kegiatan ini bertujuan agar masyarakat mengurangi penggunaan sampah plastik sehingga produksi sampah plastik di lingkungan dapat berkurang.

b. Pegurusan Surat Ijin Usaha Perdagangan (SIUP) serta Merk Dagang

Pengurusan ijin usaha perdagangan dan merk dagang ini sebagai solusi dari permasalahan pemasaran hasil kerajinan daur ulang sampah. Selain itu disusunlah daftar nama tempat yang dapat digunakan sebagai tempat pemasaran produk yang dihasilkan.

Selain itu agar nama produk lebih di kenal maka diuruskan Merk Dagang. 
Dengan harapan produk hasil kerajinan dapat dipasarkan lebih luas dan dapat meningkatkan ekonomi masyarakat.

c. Pengadaan alat daur ulang sampah plastik menjadi bahan bakar minyak (BBM)

Pengadaan alat daur ulang sampah ini bertujuan untuk mengatasi permasalahan sampah kantong plastik yang selalu diproduksi oleh masyarakat. Dengan alat daur ulang sampah plastik menjadi bahan bakar minyak (BBM) $k$ yang semula menjadi masalah dapat dijadikan hal yang bermanfaat bahka bernilai ekonomis. Selain itu dnegan adanya alat ini maka boiogas yang terdapat di UPPO Jaya Makmur dapat dimanfaatkan sebagai bahan pembakaran .

Dengan cara ini dua permasalahan penting bisa diatasi, yaitu bahaya menumpuknya sampah plastik dan diperolehnya kembali bahan bakar minyak yang merupakan salah satu bahan baku plastik. Teknologi untuk mengkonversi sampah plastik menjadi bahan bakar minyak yaitu dengan proses cracking (perekahan). Dengan ini diperlukan alat khusus untuk pengolahan sampah plastik menjadi minyak, material yang dapat membantu proses pengolahan sampah plastik menjadi minyak dan penerapannya sebagai bahan bakar mesin ${ }^{3}$.

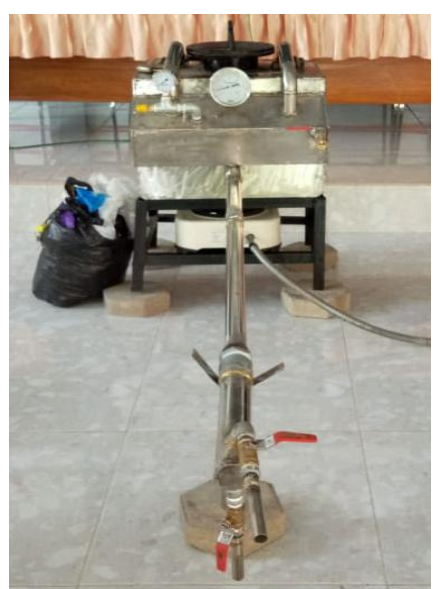

Gambar 1 Alat Daur Ulang Sampah Plastik Menjadi Bahan Bakar Minyak (BBM)

d. Sosialisasi penggunaan alat daur ulang sampah menjad bahan bakar minyak (BBM)

Kegiatan sosialisasi ini dilakukan sebelum penyerahan alat kepada mitra program kemitraan masyarakat dengan tujuan alat yang diberikan kepada mitra dapat dimanfaatkan secara optimal.

7. Evaluasi Kegiatan dan Hasil

Evaluasi kegiatan dari kegiatan yang telah dilaksanakan adalah masyarakat dapat meningkat secara kualitas dan kuantitas. Sebelum dilakukan kegiatan masyaraat belum mengetahuai tentang sampah plastik yang dapat diolah menjadi bahan bakar minyak maka setelah kegiatan masyarakat meningkat secara pengetahuan dan bahkan bernilai ekonomi lebih karena sampah plastik dapat diolah menjadi bahan bakar yang dapat dimanfaatkan untuk kehidupan. Bank Sampah Payung sejahtera sudah memiliki SIUP dan Merk Dageng sehingga produk dapat bernilai jual lebih.

\section{Pembahasan}

Pemasalahan sampah memang tidak dapat dihindarkan dari kehidupa sehari - hari, selain sampah plastik sebagian kecil dapat dimanfaatkan sebagai kerajinan tetapi sebagian besarnya dapat merusak lingkungan. Pemanfaatan dari sampah plastik tidak sebanding dengan jumlah sampah plastik yang dihasilkan, oleh karena itu kita harus meminimalkan penggunaan sampah plastik dalam kehidupan sehari - hari.

Sampah plastik yang dioleh menjadi kerajinan belum dikenal masyarakat secara luas, jika produksi terus dilakukan tanpa adanya pemasaran yang baik maka masarakat tidak berdaya secara ekonomi. Perlu adanya terobosan baru agar hasil kerajnan dapat dikenal dan dipasarkan dengan baik

Dari hasil kegiatan yang sudah dilakukan tentang pengolahan sampah plastik menjadi bahan bakar minyak di atas dapat diketahui bahwa alat yang dihasilkan dari pengolahan sampah plastik tergantung dari beberapa parameter antara lain jenis plastik yang diolah, temperatur proses, penggunaan katalis dan jenis katalis yang digunakan. Minyak dari pengolahan sampah plastik mempunyai prospek yang baik sebagai bahan bakar substitusi untuk solar maupun bensin ${ }^{4}$.

\section{Simpulan dan Saran}

Program Kemitraan Masyarakat (PKM) ini adalah program yang dilakukan bersama dengan mitra di suatu wilayah dengan tujuan dapat meningkatkan kualitas dan kemandirian 
mitra. Dalam kegiatan ini masyarakat sebagai pemeran utama dari pelaksanaan kegiatan.

Sebagain besar mitra kurang mampu untuk menggali permasalahan yang dihadapi serta menyusun solusi dari permasalahan yang ada. Dengan adanya program kemitraan ini maka bersama dengan perguruan tinggi mitra menggali permasalahan dan tahapan tahapan nya serta masalah tersebut dapat terselesaikan dengan mengoptimalkan potensi yang ada di masyarakat.

Saran untuk mitra Lebih meningkat kreasi kerajinan tangan agar dapat meningkatkan peminatan masyarakat terhadap produk olahan kerajinan sampah

UntukPemerintah Kabupaten perlu melakukan pembinaan kepada para mengrajin untuk lebih meningkatkan potensi dan keterampilannya dalam membuat kerajinan dari sampah. Dan juga Menfasilitasi pemasaran kerajinan sampah dengan mengagendakan event sehingga produk kerajinan lebih dikenal masyarakat luas

\section{Ucapan Terima Kasih}

Terima Kasih disampaikan kepada Direktorat Riset dan Pengabdian Masyarakat, Direktorat Jendral Penguatan Riset dan Pengembangan, Kementrian Riset, Teknologi dan Pendidikan Tinggi yang telah mendukung dan mendanai pengabdian masyarakat ini, serta diucapkan terimakasih kepada Poltekkes Kemenkes Semarang yang telah mendukung keberlangsungan jurnal ini.

\section{Daftar Pustaka}

Napitupulu R, Subhkan M, Nita LD. Rancang Bangun Mesin Pencacah Sampah Plastik. J Manutech. 2011;3(1):1-5.

Surono UB, Teknik J, Universitas M, Yogyakarta J. BERBAGAI METODE KONVERSI SAMPAH PLASTIK. 2005:32-40.

Damanhuri E PT. Pengelolaan sampah. Diktat kuliah, Fak Tek Sipil dan Lingkungan, Inst Teknol Bandung. 2011.

Handayani DS, Budisulistiorini SH, Nuraini MR. Pada Tpa Jatibarang Kota Semarang. J Present. 2009;7:35-44. 